\title{
Caracterização do fenótipo comportamental e de linguagem na síndrome de Williams-Beuren
}

\author{
Natalia Freitas Rossi ${ }^{1}$
}

Rossi NF. Caracterização do fenótipo comportamental e de linguagem na síndrome de Williams-Beuren [tese]. Botucatu (SP): Instituto de Biociências de Botucatu; 2010.

A síndrome de Williams-Beuren (SWB) é um distúrbio neurodesenvolvimental causado por uma deleção hemizigótica de $1.5 \mathrm{Mb}$ na região cromossômica $7 q 11.23$. Essa síndrome é reconhecida pelo comportamento sociável, com fala fluente e favorecimento das habilidades auditivas se comparadas às visuais. O objetivo deste estudo foi caracterizar o fenótipo comportamental e da linguagem na SWB. A casuística geral desta pesquisa foi formada por 40 indivíduos com diagnóstico da SWB, positivos para a deleção do gene da Elastina na região cromossômica 7q11.23 confirmado pela técnica de Hibridização in situ por Fluorescência (FISH), sendo 30 falantes do Português do Brasil e dez falantes do Português de Portugal. Também foram avaliados 30 indivíduos controles falantes do Português do Brasil e dez falantes do Português de Portugal. Para responder ao objetivo, a pesquisa foi dividida em três estudos. O objetivo do Estudo 1 foi investigar problemas comportamentais de crianças e adolescentes com a SWB, identificados pelos pais e correlacioná-los ao desempenho intelectual e de linguagem. No Estudo 2, o objetivo foi caracterizar o perfil da fluência da fala em indivíduos com a SWB na situação de narrativa, comparando-os com indivíduos com desenvolvimento típico de linguagem e idade mental. $\mathrm{O}$ objetivo do Estudo 3 foi comparar o desempenho de indivíduos com SWB com controles semelhantes por idade mental e cronológica em tarefas auditivas e visuais, além de investigar o perfil de habilidades auditivas comparadas às visuais. Foi aplicado o inventário comportamental Child Behavior Checklist (CBCL/6-18 anos), provas e testes de linguagem para o Estudo 1. Foram aplicadas tarefas em situação de narrativa, com apresentação de figura de ação e figuras sequenciais para análise da fluência no Estudo 2. O Teste Illinois de Habilidades Psicolinguísticas foi utilizado no Estudo 3. Os resultados dos estudos mostraram que problemas de atenção e problemas com contato social foram os mais referidos pelos pais dos indivíduos com a SWB. A análise de correlação sugeriu que os problemas comportamentais identificados pelos pais estão mais diretamente relacionados ao desempenho da linguagem (Estudo 1). Quanto à fluência da fala, verificou-se diferenças significantes, principalmente paras as disfluências comuns da fala e pausas com frequência mais elevada para o grupo SWB em relação aos controles. Resultado semelhante foi encontrado na comparação entre o grupo SWB de Portugal e seus controles. Não foram encontradas diferenças estatisticamente significantes entre a fluência da fala do grupo com a SWB do Brasil quando comparada à do grupo de Portugal (Estudo 2). Quanto ao desempenho no ITPA, os resultados mostraram diferenças estatisticamente significantes entre o grupo com SWB e controles por idade mental e cronológica para todas as tarefas auditivas e visuais (recepção, associação, memória sequencial e closura). O grupo com a SWB apresentou desempenho semelhante em algumas habilidades auditivas e visuais (memória sequencial e closura); e desempenho superior para outras habilidades visuais em relação às auditivas (recepção e associação). Os achados sugerem que os comportamentos predominantes, identificados pelos pais de indivíduos com a SWB apresentam correlação com o desempenho na linguagem (Estudo 1). Sugere-se que a frequência aumentada das disfluências, apresentada pelos indivíduos com a SWB do Brasil e de Portugal, na situação de narrativa, pode estar relacionada às dificuldades na elaboração e organização da linguagem (Estudo 2). Sugerem ainda que tanto as habilidades auditivas quanto as visuais estão prejudicadas na SWB, quando o ITPA foi analisado (Estudo 3).

Trabalho apresentado ao Instituto de Biociências da Universidade Estadual Paulista "Júlio de Mesquita Filho" - UNESP - Botucatu (SP), Brasil, para obtenção do título de Doutor em Ciências Biológicas, área de concentração: Genética, sob orientação da Profa. Dra. Célia Maria Giacheti.

(1) Doutora em Ciências Biológicas (Genética) pelo Instituto de Biociências da Universidade Estadual Paulista "Júlio de Mesquita Filho" - UNESP Botucatu (SP), Brasil.

Auxílio financeiro: Conselho Nacional de Desenvolvimento Científico e Tecnológico (CNPq) e Coordenação de Aperfeiçoamento de Pessoal de Nível Superior (Programa de Doutorando no Brasil com Estágio no Exterior - PDEE (processo ${ }^{\circ} 1551-08-6$ ).

Endereço para correspondência: Natália Freitas Rossi. R. Jundiái, 1215, Matão (SP), Brasil, CEP: 15990-510. E-mail: nataliafreitasrossi@yahoo.com.br 